\title{
The Hybrid Nature of Hybrid Financial Instruments and EU Steps Towards a Solution
}

\author{
Filip Djambov
}

\begin{abstract}
Over the past two years we have witnessed a very strong switch in the world of taxation. The underlying reasons or sources for it are subject to diverse interpretations, variety of viewpoints and severe discontent. The widespread view is that the game has to change entirely. However this would surely imply a reconsideration of the tax model existing for almost a century which is not viable for now. Therefore, changing the rules might yield a more desirable outcome under the condition that the modification would truly produce a satisfying result. This article examines what is the "game" (the status quo) in case of hybrid financial instruments, what are the current rules mainly in an European Union (EU) context and if a change under the proposed amendments to the ParentSubsidiary Directive 2011/96/EU would in reality make the "game" as enjoyable as before or at least acceptable. ${ }^{1}$
\end{abstract}

\section{Introduction}

For the last few years, aggressive tax planning, tax avoidance, tax fraud and their various manifestations have been dominating the public and private sector. Issues raised by numerous forms of base erosion and profit shifting are listed as top priorities for EU and non-EU countries. Logically, states want to optimize the levy of taxes and obtain the corresponding revenues attributable to their jurisdiction. At the same time, companies want to increase the profit margins through the

1 Proposal for a Council Directive amending Directive 2011/96/EU on the common system of taxation applicable in the case of parent companies and subsidiaries in different Member States, COM(2013) 814 final (25 Nov. 2013) 
optimization of all the costs concerned, including optimal taxation. The opposing interests involved might seem irreconcilable having in mind the stakes at hand. In the quest to achieve at least a certain level of balance, the parties engaged are required to adopt solutions that take into account the long-term objectives, the legal certainty behind the rules and potential ramifications of the latter.

This article focuses on a particular set of arrangements through which companies attempt to obtain the most favourable taxation and increase the yield on their investments. The aforesaid are carried out by means of exploitation of complex hybrid financial instrument schemes. The significant impact of these sophisticated instruments on the taxing rights of countries has raised various questions but still no concrete answers. The inner logic behind a hybrid instrument is to utilize the differences between the divergent tax systems. The EU, along with the OECD's work on base erosion and profit shifting and in the context of combating the negative effects of hybrid mismatches, decided to propose an amendment to the Parent-Subsidiary Directive by conditioning the tax relief provided by a home Member State to the deductibility at the level of a host Member State. This approach addresses only one possible solution to the problem and leaves aside other significant ones.

The underlying idea of the article is not to contemplate on whether the EU solution is the right path to take or not. The objective is to provide various points of views and to look at the hybrid mismatch outcome from the perspective of a world that is more and more interconnected and where the various elements of the many tax systems are in a constant interaction.

\section{The Risk of Double Taxation or Non- taxation}

Transactions related to cross-border hybrid financial instruments have been subject to an increased degree of scrutiny. The reason for this is the specific results these types of arrangements give in an international tax planning aspect and the concerns related to their outcome once put into practice. From a State point of view, the risks associated with the use of these kind of international tax arbitrage transactions is the fact that a taxpayer attempts to benefit from the different treatment of the instrument in two or more jurisdiction. The hybrids make sense only in a cross-border situation and none of the jurisdictions involved can blame the other for the loss of tax revenue as a result of their application. 
In general, double taxation occurs when two or more jurisdictions assert taxing rights to income arising in a Contracting State without providing relief for the taxes paid in that State. As a result both countries tax the income and this outcome has harmful effects on the taxpayer. However, it frequently happens so that the taxpayer can minimize or even eliminate the tax liability so no or very little tax is paid, i.e. double nontaxation, which is not less unwanted compared to being subject to double taxation. In the sphere of hybrid instruments the two sides of the coin (double taxation or double non-taxation) are manifestly present. Through the inconsistent qualification given in different tax systems the treatment of hybrid instruments can lead to both double taxation and opportunities for tax arbitrage.

\section{Hybrid Financial Instruments:}

To understand the anti-avoidance actions taken in the last two years in combatting the adverse effects that hybrid financial instruments produce it is essential to examine their nature and the qualification complexities they raise. In March 2012, the OECD published a report titled 'Hybrid Mismatch Arrangements, Tax Policy and Compliance Issues' which addresses four types of hybrid mismatch arrangements, ${ }^{2}$ among others: hybrid instruments 'which are treated differently for tax purposes in the countries involved, most prominently as debt in one country and as equity in another country'. Hence there is a possibility that country A will treat the instrument as debt and country B as equity. The mismatch problem lays in the fact that the rules demarcating debt and equity for tax purposes differ from one country to another. The hybrid instrument enables the taxpayer to create a class of transaction with disparate international tax treatment 3 the result of which is deduction of the interest expense in one country and no inclusion in the taxable income in the other one (the so called deduction/no inclusion result). The exploitation of these discrepancies between the tax regimes, thus reducing the effective tax rate to nothing or to a very low amount, is seen as aggressive tax planning and as such unacceptable. ${ }^{4}$

2 OECD, Hybrid Mismatch Arrangements: Tax Policy and Compliance Issues, p.10 (OECD 2012)

3 Andriy Krahmal, "International Hybrid Instruments: Jurisdiction Dependent Characterization", Houston business and tax law journal [1543-2602], 2005, vol.5, p.98

4 C (2012) 8806 final, p. 2. 
The inherent difficulty in distinguishing between debt and equity partly comes from the proliferation of contemporary sophisticated instruments in the financial sector where the component parts of a specific instrument are very much diluted and overlapping. This factor in combination with diverse categorizations of an instrument under the domestic law of a country results in insurmountable qualification problems aptly exploited by subtle hybrid arrangements. In addition, what makes the hybrid financial instruments so undesirable from a tax policy standpoint is that the use of them per se is not prohibited; on the contrary, it is a legitimate way of financing the business activities of a company in one jurisdiction or a way to obtain better profits on an investment through the existing disparities. For this reason when characterizing hybrid financial instruments a referral is made to the notion of tax arbitrage. This clarification is of particular relevance when comparing this type of transaction to other practices of tax abusive nature. The importance of this distinction has been implicitly recognized by OECD when examining the various possible policy solutions adopted in domestic laws. ${ }^{5}$

What makes tax arbitrage different from tax avoidance is the definition of the former as a set of transactions designed to take advantage of the different tax system in order to achieve no taxation or very low such ${ }^{6}$. The hybrid financial instruments come under this definition and as such are seen as a manifestation of it. It is important to make a few illustrations on how tax arbitrage functions before drawing any conclusions. As already mentioned the main objective is to combine the most opportune tax treatment between two jurisdictions so to secure an interest deduction for the foreign entity and an unburdened payment at the level of the recipient entity. For instance, the distributions on jouissance shares ${ }^{7}$ in Germany are deductible under certain conditions. Meanwhile, in the U.S. they will be treated as having equity characteristics and as such, a distribution of dividends to the investors is recognized. ${ }^{8}$ The inconsistency derives from the fact that in the U.S. factors such as fixed maturity, whether the return represents a legally enforceable claim; whether such a claim is subordinate to the claims of general creditors; and whether its holder has voting rights are taken

5 OECD, supra n.2, Chapter 3

6 Prof. Reuven S. Avi-Yonah, "Tax Competition, Tax Arbitrage and the International Tax Regime",

7 Stephan Trapp, "Taxation of Hybrid Instruments", Germany, 1999 IBFD Publications BV Comparative Survey, Derivatives \& Financial Instruments, Vol.1, No.6

8 Supra n.2, p.12. 
into account ${ }^{9}$. On the other side of the transaction, the payments are deductible in Germany if the holder is not entitled to participate in both the enterprise's profits and a potential liquidation profit. As long as at least one of the conditions is not met, especially if only a participation in the profits is granted the distribution is considered deductible.

The rules differ from one jurisdiction to another. In France, the classification of a financial instrument is based mostly on whether voting rights are conferred on the holder or not ${ }^{10}$. Still under Art 10 of the OECD Model Tax Convention on Income and Capital (2010-2012), the existence of shareholder voting rights is not decisive for the qualification of whether an instrument contains more debt or equity characteristics, as long as a shareholder participates in both the current profits and any eventual liquidation proceeds of a company and faces the entrepreneurial risk of a total loss of the capital invested. ${ }^{11}$ Another example of an inconsistent treatment of a financial instrument is the Dutch perpetual loan that can be regarded as equity, because of the fact that the principal will never be reimbursed, but as debt-like due to the lack of voting rights, risk assumed in the business of the entity, because of a pre-established coupon rate, priority in the liquidation and others.

The redeemable preference shares are another example of a possible hybrid mismatch that provides for a tax saving. Dutch case law provides an interesting situation for a cross-border arrangement that clearly illustrates a tax arbitrage situation. ${ }^{12}$ The restructuring of a shareholder loan granted to an Australian company into redeemable preference shares under which the Dutch participation exemptions was applicable, at the same time under Australian tax law a deduction of the interest payment was still enjoyed, significantly lowered the tax liability of the Dutch shareholder. The taxpayer benefited from an existing mismatch

9 Niels Johannesen, "Tax avoidance with cross-border hybrid instruments", Journal of public economics [0047-2727], 2014, Vol.112, p.40-52

10 See id. n.9

11 Prof. Marjaana Helminen, University of Helsinki, "Classification of Cross-Border Payments on Hybrid Instruments", 2004 IBFD, Bulletin for International Taxation, Vol. 58, No. 2; Commentaries on the Articles of the Model Tax Convention on Income and Capital, art. 10 par. 24-25

12 Gabriël van Gelder and Boudewijn Niels, "Netherlands, Tax Treatment of Hybrid Finance Instruments" Derivatives \& Financial Instruments, 2013 (Volume 15), No. 4, 2013, point 3.3.1; case law AC Amsterdam (Gerechtshof Amsterdam), 7 June 2012, 11/00174, VN 2012/40.11 
between the two tax systems and there is no legal basis on which to consider whether the Dutch classification (equity-like distribution of profits and a following exemption of the income from taxation) or the Australian one (debt-like and the following deduction of the interest expenses) is correct or incorrect. The examples demonstrate the uncompromising nature of the different rules applicable to hybrid financial instruments. In this complex network of interplaying characterizations there are no clear answers. The situation can even get more complicated where the use of the financial instrument involves conduit entities in several countries; where instead of having the divergent interpretation of only the host and the home tax systems an additional third jurisdiction is exploited. This multiple jurisdictional approach might mitigate the risks of reclassification of the instrument and avoid a possible denial of the benefits obtained.

The inherent complexity around the hybrid financial instruments, as inferred from the examples above, is due to the country-specific tax environment. This point is of particular relevance upon the introduction of an effective solution that can identify all the specificities of the hybrid instruments. Each country adopts certain provisions that reflect existing economic circumstances at a given time frame. The jurisdictional reach of these provisions in many occasions proves to be limited in its material scope and at the same time not in pace with the incessantly innovative financial world. The recognition of all these developments and changes can be a challenging task for not only relatively developed countries. The contemporary financial products frequently do not provide for comparable transactions to serve as a benchmark. A financial product allows for a risk diversification and segregation of the composing elements with the objective to match the specific needs of the parties involved. This makes the characterization of an instrument unclear and gives way to legitimate manipulations. All this taken into account in combination with the attempts on part of many countries to restore the missing legal certainty when dealing with hybrid financial instruments provides for numerous opportunities for tax arbitrage. The diversity among tax jurisdictions do not create possibilities for tax arbitrage on in its own merits. ${ }^{13}$ The disparities originate where tax and economic distinctions do not match, or when the tax law provides a distinction but the economics of the transaction do not warrant one, thus allowing the taxpayer to elect the tax results without varying his underlying economic position. If such asymmetries of the two or more

13 See id. n.2 
international tax systems are inconsistent, the arbitrage opportunities arise'. ${ }^{14}$

When solving these policy issues countries are very meticulous about preserving the delicate balance between protecting the tax base from being eroded and the same not to unduly discourage the use of new financial instruments. Even though the last statement is contradictory in itself it certainly holds some merits on why the current rules of the game cannot be changed that easily. It has been stated that there is existing uncoordinated policy equilibrium in the treatment of hybrid financial instruments. ${ }^{15}$

From the perspective of the host state, stringent anti hybrid rules, the introduction of an effective taxation of the distributing entity or the disallowance of the deductibility of the interest payments would impair the established equilibrium. The same applies from the perspective of the home country mutatis mutandis. This is premised on the high mobility of capital being shifted to another jurisdiction where no such strict rules apply. As a result, the incidence of the tax would fall on the less mobile labor force and produce suboptimal effects. Apart from the latter, the ban on hybrid instruments will also have another consequence. It will certainly increase the tax base of the countries involved, but at the same time it will impact the ability of multinational companies to remain globally competitive, unless countries lower the tax rate in order to attract business back.

\section{EU Response}

In the last two years the outcome of the exploitation of hybrid financial instruments has become a serious concern for law makers. What are the causes for the late response to this type of transactions, used for over two decades, is of no importance. The relevant question is whether a partial modification of the tax treatment would bring into practice a balanced outcome that would address the idiosyncrasies of these financial products, which in the end pursue a legitimate financing aim. The existing framework is obviously not operative, neither effective, nor acceptable. The anti-abusive rules are not always applicable to

14 See id. n.2, p.33

15 See id. n.8; Q. Hong, M. Smart "In praise of tax havens: international tax planning and foreign direct investment", European economic review, ISSN 0014-2921, 2010, Vol. 54, Issue 1, p.82 - 95 
situations of tax arbitrage, which requires compliance with the tax rules in each jurisdiction where the effects of the transaction take place.

At an EU level the risks involved in the use of hybrid financial instruments, as part of the broad concept of tax arbitrage have been identified indirectly by the Commission stating that the lack of coordination may also lead to unintended non-taxation and provide scope for abuse. Non-taxation and abuse are equally detrimental to the interests of the Internal Market because they undermine the fairness and the balance of Member States' tax systems. This problem can also be addressed by better co-ordination of Member States' rules and improved co-operation with respect to enforcement. This will be an essential element of the Commission's initiatives, and the Commission proposes to examine this area together with Member States in a working group in the near future depending on the progress of relevant EC] case law'. ${ }^{16}$

Later on (2007) the Commission referred directly to the unwanted results caused by hybrids: 'Lack of concerted interaction between MSs tax systems may result in unintended non-taxation and provide scope for abuse, thus undermining their fairness and balance. Mismatches may arise, for example, in relation to the qualification of debt and equity. One MS may consider a transaction to be an equity injection and thereby exempt the income derived from it (as profit distribution), whereas another MS may consider the same transaction to be a loan and allow tax deductibility for the consequent payments (as interest). This may result in a deduction in one MS without corresponding taxation in another MS... Such problems are best tackled at source, by reducing the occurrence of mismatches'. ${ }^{17}$

From these statements the logical conclusion is that the Commission doesn't seem to consider tax arbitrage per se, as abusive. However whether the results that it leads to, i.e. double non-taxation, through hybrid arrangements, can constitute an abuse is a different situation. Can it be said then that it is possible to bring the use of hybrid financial instruments under the anti-abuse provisions included in Art 1(2) of the

16 Communication of 19 December 2006 from the Commission to the Council, the European Parliament and the European Economic and Social Committee - Coordinating Member States' direct tax systems in the Internal Market $\operatorname{COM(2006)} 823$ final, p.2.3

17 Communication from the Commission to the Council, the European Parliament and the European Economic and Social Committee, $\operatorname{COM}(2007) 785$ final, p.6 
Parent-Subsidiary Directive ${ }^{18}$ ? In order to provide an answer on what are the conditions for a certain transaction to be found as abusive and fraudulent ${ }^{19} \mathrm{ECJ}$ 's findings can be integrated into the analysis. This is important due to the autonomous interpretation of the concept of tax abuse within the EU. The Cadbury Schweppes case ${ }^{20}$ provides the necessary guidelines stating that the anti-abuse measures should target 'wholly artificial arrangements aimed at circumventing the application of the legislation of the Member State concerned' that 'do not reflect economic reality, with a view to escaping the tax normally due on the profits generated by activities carried out on national territory'. ${ }^{21}$ So in order to have an abusive situation in the field of direct taxation the necessary elements to look at are the factors related to the artificially of the establishment (objective test that examines the substance of the entity); artificiality of the transaction (subjective test that examines the lack of any genuine business purpose) and third, if the terms of the transaction are at arm's length ${ }^{22}$. When analyzing the elements of the subjective test the tax saving purpose of the arrangement carried out is no longer deemed essential and it doesn't constitute abuse on its own basis if the transaction reflects economic reality ${ }^{23}$. In the context of hybrid financial instruments this means that for these types of arrangements it would be rather difficult to substantiate the presence of an abusive practice based solely on the underlying savings motive. As already mentioned, the dual nature of the instrument derives from the divergent classification given by the MS involved in the transaction. However in most cases they pursue a legitimate financing aim that cannot be automatically discarded or qualified as abusive ${ }^{24}$. As a result

18 For the sake of this paper the Interest and Royalties Directive is out of the scope. However under the latter Art 4 specifically deals with situations of hybrid financial instruments.

19 Jakob Bundgaard, "Classification and Treatment of Hybrid Financial Instruments and Income Derived Therefrom under EU Corporate Tax Directives - Part 2", IBFD, European Taxation, Vol.50, No.11, p.3-11; Jakob Bundgaard, "Hybrid Financial Instruments and Primary EU Law Part 2",IBFD, European Taxation, 2013, Vol.53, No 12, p.6.8

20

21 C-196/04 Cadbury Schweppes plc, Cadbury Schweppes Overseas Ltd

v. Commissioners of Inland Revenue, 12 September 2006, Supra par.52 and 55

22Alina Armenia and Adam Zalasinski, "The taxation of foreign passive income for groups of companies", EU Report, Volume 98A, 2013, , p.66

23 Supra n.21, p.66; Supra n.18 p.4

24 Supra n.19, par. 65-66 
the use of hybrid financial instruments remains outside the scope of the anti-abuse provision in the Parent-Subsidiary Directive.

In support of the latter statement is the fact that within the EU MS are free to organize national tax systems at their own sovereign discretion and none of the members has the legal obligation under EU law to adapt and comply with the others jurisdiction as long as they do not act against the main principles and freedoms of EU law. As stated briefly, hybrid mismatch makes sense and occurs only in a cross-border situation, i.e. when at least two jurisdictions are engaged. It is a twocountry problem in having uncoordinated and unharmonized tax rules within the framework of differing independent legal systems. This effect is widely referred to as a disparity. If we imagine a situation where two jurisdictions have the same legal system, in such a case the tax saving caused by the exploitation of a hybrid will disappear. This solution though at the current state of affairs will only remain in the realm of good wishes. The ECJ had the chance in various instances to state that disparities are not within the scope of the prohibitions of the treaty freedoms and since there is no harmonization in the field of direct taxation no remedy can be provided: 'Member State is not (added by the author) required to draw up its tax rules on the basis of those in another Member State in order to ensure, in all circumstances, taxation which removes any disparities arising from national tax rules'. ${ }^{25}$ Further, it has been recognized by ECJ that sometimes juridical double taxation cannot be avoided and it is a matter of exercise in parallel of the fiscal sovereignty of a country and thus acceptable. ${ }^{26}$ On the contrary, double non-taxation caused by deduction at source and non-inclusion at residence, i.e. the normal implications of a hybrid instrument, should be tackled by all means even if eventually double taxation might occur. The attempt to deal with an inconsistent situation through lack of consistency in the conceptual approach can result in adverse consequences.

Under the current rules in the PSD it has been argued whether the directive benefits can be denied if the payment gives rise to a deduction in the source state. As already described the use of hybrid financial instruments in most cases shall not constitute an abusive practice. The fact that the paying company is established in a low tax jurisdiction cannot be opposed as long as it is not a purely artificial arrangement

25 C-157/07 Finanzamt für Körperschaften III in Berlin v. Krankenheim Ruhesitz am Wannsee-Seniorenheimstatt GmbH, 23 October 2008, par. 50

26 C-513/04 Mark Kerckhaert and Bernadette Morres v. Belgische Staat, 14 November 2006, par. 20 
and as long as it reflects a real economic activity. This is based on numerous examples from the jurisprudence of the ECJ. The case law states that any advantage derived from the low level of taxation at source cannot be given as a justification by the residence state in providing a less favourable treatment. ${ }^{27}$ The same is valid for any other existing advantage that has been granted and to which the other state attaches less beneficial tax treatment. ${ }^{28}$ Even in the case of a twofold advantage - a relief in the state of residence and in the state in which the dividend was paid, the justification was rejected ${ }^{29}$. Therefore, compensatory tax arrangements cannot serve as a basis ${ }^{30}$ on which to deny the applicability of PSD and as a result the benefits a qualified entity is entitled to. Further, the PSD provides for a subject to tax condition in Article 2(a)(iii). ${ }^{31}$. From that provision it cannot be concluded that the fact that the payment might be deductible at source means that a company doesn't comply with this requirement. The deduction certainly reduces the overall tax liability of the company but it cannot be placed on the same footing as a company that is not liable to tax and as such having exempt income.

For these reasons, under the current version of the PSD it is difficult to deny the benefits of the PSD when hybrid financial instruments are involved. In order to prevent this type of tax arbitrage and because of the fact that ECJ is unwilling to apply a teleological interpretation to limit the scope of the PSD it has been acknowledge that a specific rule has to be incorporated into the text of the directive. ${ }^{32}$ This approach may create legal uncertainty and also go against the initial objectives of the PSD. The introduction of a single new rule, which can effectively tackle the use of hybrids and that can encompass all the specificities of those financial products, within the current legal framework of the directive, will most probably produce counter effects that will be not less unwanted.

27 See id. n.19, par. 49

28 C-315/02 Anneliese Lenz v. Finanzlandesdirektion für Tirol, 15 July 2004, par. 41-43

29 C-35/98 Staatssecretaris van Financiën v. B.G.M. Verkooijen, 6 June 2000, par. 54 and par. 61

30 C-294/97 Eurowings Luftverkehrs AG v. Finanzamt Dortmund-Unna, 26 October 1999, par.43-45

31 A company which is 'subject to one of the taxes listed in Annex I, Part B, without the possibility of an option or of being exempt'.

32 Jakob Bundgaard, "Classification and Treatment of Hybrid Financial Instruments and Income Derived Therefrom under EU Corporate Tax Directives - Part 2", p. 7 


\section{The Proposal for Change}

Under these circumstances, the potential inefficiencies caused by the use of hybrid financial instruments have been addressed by the European Commission as an area that calls for immediate actions. The Commission issued an Action plan in order to improve the fight against tax fraud and tax evasion. ${ }^{33}$ Recognizing the weaknesses of the current regime, the various loopholes created and the numerous possibilities for tax planning; in point 14 of the Action plan it provided for a revision of the PSD. As previously stated, the only feasible way to deal with hybrid mismatches under the PSD is through a legislative amendment. The objective of this action is to ensure that 'the application of the directive does not inadvertently prevent effective action against double nontaxation in the area of hybrid loan structures'. The initiative of the Commission is a commendable undertaking in the global fight against tax avoidance and in line with the steps undertaken by the OECD that launched its corresponding version of the necessary actions against base erosion and profit shifting, namely BEPS ${ }^{34}$. In order to prevent the double non-taxation resulting from deduction and non-inclusion schemes using hybrid instruments treated differently in the countries involved there are two generally accepted approaches: to condition the deductibility of interest payments to foreign entities on taxation in the home country and condition exemption of dividends from foreign entities on non-deductibility in the host country. The Commission decided to choose the second option- according to the proposed Article 4(1)(a), a tax exemption shall only be provided 'to the extent that such profits are not deductible by the subsidiary of the parent company, ${ }^{35}$ i.e. if deductible then the state of the receiving company shall tax the portion of the profit distribution payments which is deductible in the Member State of the paying subsidiary.

The proposed amendment raises some doubts as to its clarity and precision of the wording, the objective pursued and the international tax developments in the field of double non-taxation resulting from hybrid mismatches. It is unclear whether the proposal by limiting the obligation of the parent company under the new Article 4(1)(a) 'shall refrain to the extent' also prevents the latter from providing an exemption upon

$33 \operatorname{COM}(2012) 722$ final

34 OECD, Addressing Base Erosion and Profit Shifting, Action 2 (OECD 2013)

$35 \operatorname{COM}(2013) 814$ final 
distribution of profits that have been deducted by the distributing company ('the benefits of the tax exemption should be denied to distribution of profits that are deductible $\left.{ }^{\prime 36}\right) .{ }^{37}$ Another issue that has not been addressed by the anti-hybrid rule is how to effectively combat conduit hybrid structures involving the use of a hybrid financial instrument at multi levels through setting a chain of entities. Probably the most serious concern would be the interplay between the proposed amendment (deductibility and no exemption) and the introduction of 'circularly linked rules' as suggested by the OECD. ${ }^{38}$ Through the latter approach the treatment of a hybrid is based on the literal compliance with the laws of both states and it follows the treatment of the foreign state (denial of deductibility of tax exempt distributions at the level of the recipient). Without going into much detail a possible consequence of such a lack of coordination of international rules might be the same (deduction/non-inclusion) or it might actually lead to the other extreme of double taxation. Both outcomes have been recognized as undesired from a tax policy perspective, however, the latter seems to some extent rather acceptable. Unfortunately, the real reason to engage in tax arbitrage involving hybrid financial instruments (the lack of explicitness in the law and the divergent domestic laws) has not been identified. The introduction of a single standing rule that is expected to deal effectively with a very complicated maze of transactions is definitely an ambitious act.

\section{Conclusion}

At this point in time the anti-hybrid rule proposal has already been backed by the European Parliament and even more it is supported by the majority of the MS. Undoubtedly, it represents a major step forward in the fight against aggressive tax planning. The hybrid mismatch action of the Commission came into being before the OECD's Discussion Draft on Hybrid Mismatch Arrangements ${ }^{39}$ and most probably will become

36 See id. n.34, p.6 Recitals

37 Christoph Marchgraber, "Tackling Deduction and Non-Inclusion Schemes - The Proposal of the European Commission", IBFD, European Taxation, 2014, p.3

38 Public Discussion Draft, BEPS ACTION 2: NEUTRALISE THE EFFECTS OF HYBRID MISMATCH ARRANGEMENTS

(Recommendations for Domestic Laws) 19 March 2014 - 2 May 2014

38 See id. n. 37 
reality before the latter takes effect. The Commission's proposal to curb the use of hybrids developed in a relatively short period of time and if it goes as planned the amendments will be adopted by September 2014. It is the hope of everyone that the decision of the Commission is well grounded and reflects a deep understanding of the real nature of these specific financial transactions otherwise it will bring additional complexities and it would impact negatively the competitiveness of the EU. It cannot be ruled out that from inadvertent double non-taxation a switch to inadvertent double taxation might occur. 